\title{
Editorial
}

\section{Special Issue for Building Energy Conservation and Renewable Energy Integration}

With the development of society and the improvement of people's living standards, the thermal comfort requirement of indoor environment is increasing, which leads to more and more energy consumption. It is essential to scientifically develop, strategically promote and practically implement building energy saving techniques.

Generally speaking, there are four basic approaches for building energy saving, namely, optimizing building design (e.g. Improving the insulation of the enclosure, optimizing building form); applying building equipment with high energy efficiency (e.g. high energy efficiency air conditioner, energy saving lamps); advanced building energy supply system (e.g. distributed energy system, the application of renewable energy); and optimizing equipment operation and control.

With the support from authors and reviewers, 13 original research papers and one review paper have been accepted in this special issue. In this special issue, the 13 papers cover the first three pathway described above, besides, there are several studies on energy saving evaluation tools or models, e.g. "A quantitative process-based inventory study on material embodied carbon emissions of residential, office, and commercial buildings in China", "Development and application of evaluation index system and model for existing building green-retrofitting".

The topics of the Special Issue on the Building Energy
Conservation and Renewable Energy Integration are related to a wider coverage of innovative research and studies on the building energy saving techniques. We believe the current Special Issue of Journal of Thermal Science will be of interest and relevance to a broad scope of the scientific community. Moreover, we hope this Special Issue can attract more attention to the topic of building energy conservation and renewable energy integration.

Finally, it is a pleasure that we were given the opportunity to edit this Special Issue. We would like to thank all the contributors of this Special Issue for their support and cooperation. We also thank all the reviewers for their critical comments to ensure the academic quality of this Special Issue.

Guest Editors Associate Prof. LIU Zhijian

North China Electric Power University, Baoding, China

E-Mail: zhijianliu@ncepu.edu.cn

Prof. LI Hongqiang

Hunan University, Changsha, China

E-Mail: 1hq@hnu.edu.cn

Dr. LI Guiqiang

University of Hull, Hull, UK

E-Mail: Guiqiang.Li@hull.ac.uk 